\title{
A VISÃO CONTEMPORÂNEA DO FRACASSO ESCOLAR SOB A PERSPECTIVA CIENTÍFICA
}

\author{
Gleicione Apa. Dias Bagne de SOUZA ${ }^{1}$ \\ Cláudia Aparecida NASCIMENTO² \\ Luciana Alves de OLIVEIRA ${ }^{3}$
}

${ }^{1}$ Reitora e Pró-reitora de Graduação e Assuntos Acadêmicos da Universidade Vale do Rio Verde UninCor.

${ }^{2}$ Psicopedagoga Institucional e Clínica.

${ }^{3}$ Psicopedagoga Institucional e Clínica.

Recebido em: 15/05/2014 - Aprovado em: 15/07/2014 - Disponibilizado em: 30/07/2014

RESUMO: Este trabalho tem por objetivo analisar os conceitos de fracasso escolar e suas concepções mediante as diferentes visões literárias e científicas dentro das Ciências Humanas e da Saúde, evidenciando-se a área educacional e escolar. Serão abordadas as definições de sintoma escolar e sua relação com os processos de aprendizagem e suas dificuldades, e, consequentemente o fracasso escolar sob a perspectiva psicopedagógica. Discutir-se-á como o aprendente é afetado em sua totalidade, ou seja, como o fracasso escolar afeta o ser íntimo e o ser social com questões internas (estruturais, deficiências sensoriais graves genéticas ou adquiridas) e externas (vivência, acontecimentos, relações).

Palavras-chave: Fracasso Escolar, Aprendizagem, Psicopedagogia

\begin{abstract}
This study aims to examine the concepts of school failure and their conceptions through the different literary and scientific views within Social and Health Sciences, putting school and educational area on top. The symptom of school settings and their relation to the learning processes and difficulties will be pointed, and consequently the school failure from the psychopedagogic perspective. Also, will be discussed how learning is affected in its entirety, in other words, how school failure affects the intimate and social being with internal (structural, severe sensorial problems, genetic or acquired) and external issues (existence, events, relationships).
\end{abstract}

Keywords: School failure, Learning, Psychopedagogy

\section{1-INTRODUÇÃO}

O fracasso escolar é uma patologia recente decorrente da instauração da escolaridade obrigatória, fim do século XIX. Para melhor entender o fracasso escolar, fazse necessário falar sobre as dificuldades de aprendizagem, pois elas acabam por desencadeá-lo. O processo de aprendizagem é o objeto de estudo da psicopedagogia, a qual age para a superação dessas dificuldades sob um caráter institucional ou clínico.

Num breve referencial às abordagens de autores que estudaram os sintomas que se 
relacionam ao fracasso escolar e as dificuldades de aprendizagem, pode-se citar: Cordié (1996) afirma que o fracasso, opondose ao sucesso, implica um julgamento de valor como uma função de ideal. Durante a existência de um sujeito, ele se constrói perseguindo ideais, essencialmente os de seu meio sócio-cultural ou os ditados pelos valores familiares (modelos), tornando-se assim o produto de suas identificações sucessivas, que formam a trama de seu ego.

Por Lacan(1979) tem-se então, que enquanto o sujeito neurótico é dividido pelo recalcamento, o sujeito psicótico é dividido pela foraclusão. Este conceito é utilizado referindo-se ao termo freudiano Verwerfung, designando um mecanismo específico da psicose, por meio do qual o sujeito rejeita um significante fundamental para fora do seu universo simbólico. Quando ocorre essa foraclusão, um significante primordial é rejeitado no universo simbólico, não se integra ao inconsciente, como ocorre com os neuróticos sob a forma de recalque. Esse significante foracluído retorna então (no real) para o sujeito, como uma alucinação ou um delírio que invadem sua fala ou a sua percepção.

Sisto (2001) argumenta que o termo dificuldades de aprendizagem engloba um grupo heterogêneo de transtornos, manifestando-se por meio de atrasos ou certos tipos de dificuldades e ainda refere-se à importância de olhar os aspectos orgânicos, afetivos e pedagógicos que levam o aluno a não aprender.

Segundo Bossa (2002) quando o sintoma se apresenta como problema na aprendizagem escolar, encontra terreno fértil e ocupa posição privilegiada no mundo em que vivemos, definindo a direção da intervenção.

$\mathrm{Na}$ visão de Fernandez(1995), o indivíduo em processo de aprendizagem que apresenta dificuldades no aprender, pode estar desenvolvendo um mecanismo único para suportar as alterações de sua história emocional. Assim, pode-se entender o fracasso como sendo um sintoma, segundo a autora, ou seja, um tipo de obstáculo no aprender que desenvolve uma interseção de aspectos sociais, culturais, familiares, orgânicos, pedagógicos, como também fatores afetivos e intrapsíquicos.

\section{O FRACASSO ESCOLAR VISTO}

\section{COMO SINTOMA}

Atualmente, não só no Brasil, mas também nos demais países do mundo, considera-se o fracasso escolar como um sintoma que atinge a maior parte dos processos educacionais.

Para Cordié (1996, p.17):

O fracasso escolar é uma patologia recente. Só pôde surgir com a instauração da escolaridade obrigatória no fim do século XIX e tomou um lugar considerável nas preocupações de nossos contemporâneos em conseqüência de uma mudança radical da sociedade. Também nesse caso, não é somente a exigência da sociedade moderna que 
causa os distúrbios, como se pensa frequentemente, mas um sujeito que expressa seu mal-estar na linguagem de uma época em que o poder do dinheiro e o sucesso social são valores predominantes. A pressão social serve de agente de cristalização de um distúrbio que se inscreve de forma singular na história de cada um.

Mas, que lugar esse novo sintoma ocupa na sociedade atual? Pois, o que seria de se esperar, neste momento, é que houvesse um aumento na capacidade de aprender dos sujeitos, devido ao uso das novas tecnologias e à ampliação dos sistemas de ensino.

$\mathrm{Na}$ concepção de Cordié o fracasso escolar não apresenta uma única causa, ele é multicausal. Há sempre uma conjunção de várias causas que, agindo umas sobre as outras, interferem, dificultando sair de uma espécie de círculo vicioso, o que emerge na educação, muitas vezes, uma ação sem sujeito. Ou ainda um sujeito sem saber porque age de determinada forma, um sujeito que age por impulso sem pensar, ou sob o impacto de uma emocionalidade muito grande.

A conexão ato e pensamento nas escolas encontra-se fragilizada. O problema não se trata apenas de processos referidos aos agentes da educação. Mas, há algo muito maior que os apreendem e capturam, fixandoos a um determinado contexto social, a uma determinada situação.

O fenômeno é mais grave e se instala nos sujeitos por meio da sua interação com a linguagem e a fala.

O que espera-se dos sintomas educacionais é a normatização das pessoas.
Essa tentativa de encaixar todos os sujeitos dentro de um parâmetro de normalidade acaba por desencadear a exclusão dos alunos diferentes ou deficientes das salas de aula comuns.

Então, o fracasso escolar não é apenas um sintoma objetivo, socialmente determinado. Ele se transformou em um sintoma subjetivo, internalizado por vários sujeitos aprendentes e sujeitos ensinantes do ambiente escolar.

\subsection{O sentido dos sintomas}

Neste subtítulo, evidenciou-se o sentido dos sintomas para a medicina e para a psicanálise, onde este tem valor de signo (processo mórbido, doença, manifestações objetivas) e significante (estrutura simbólica que o torna decifrável pelo trabalho interpretativo do sujeito, manifestações subjetivas) respectivamente.

Conforme relata Freud (1926) na psicanálise, não há sintoma em si, só há sintomas particulares, "há um sujeito que, uma vez eclipsado, só pode ser ouvido a partir do seu sintoma”, ou seja, neste caso, é uma forma do sujeito falar quando já não consegue ou não sabe expressar-se por meio de palavras.

Nesse amplo universo de investigação exige-se uma abordagem pluridisciplinar dos sintomas, sem cair nos riscos fáceis de se tornar incoerente por força das discrepâncias 
entre alguns paradigmas das teorias, quando erroneamente aplicadas.

Cordié (1996) nos alerta para os perigos teóricos e técnicos dos grandes sistemas que tentando realizar uma síntese de diversos corpus epistêmicos, terminam por criar uma nova teoria, uma outra modalidade. Assim, alerta Cordié que não é bom que os ensinantes se ponham a fazer interpretações psicanalíticas ou que os analistas se façam de pedagogos ou de assistentes sociais.

No encontro entre o ensinante e o aprendente, perpassa uma linha invisível (e indizível) do desejo. Todo desejo remete à nossa incompletude, à uma falta que reivindica satisfação, algo da ordem muito singular, do sujeito, tanto do que ensina quanto do que aprende. O arranjo desejante é um arranjo de comunicações metalingüísticas relacionadas de alguma forma ao desejo de saber e ao desejo de poder de cada um dos componentes da dinâmica ensinar-aprender.

\subsection{O Fracasso Escolar como revelação do}

\section{sujeito}

O próprio termo "fracasso" já implica em um julgamento de valor, lembra Cordié, em seu livro “Os Atrasados não Existem”, no qual trata da psicanálise de crianças com fracasso escolar. A autora afirma:

Ser bem-sucedido na escola é ter uma perspectiva do ter, mais, tarde, um a bela situação, de ter acesso, portanto, ao consumo de bens. Significa também 'ser alguém', isto é, possuir o falo imaginário, ser considerado, respeitado. O dinheiro e o poder, não são eles a felicidade? (...) O fracasso escolar pressupõe a renúncia a tudo isso, a renúncia ao gozo. $(1996,21)$

Há caracterizações do fracasso escolar como uma característica social da contemporaneidade. Torna-se imprescindível identificar em que circunstâncias um comportamento culturalmente determinado torna-se sintomático.

Encontra-se, pois, diante de múltiplas variações do desejo. Ou seja, identifica-se no campo específico da psicanálise que é convocada a dissertar sobre a questão do fracasso escolar, fracasso este, entendido já desde uma outra perspectiva, que é a de um sintoma de uma espécie de mal-estar sóciocultural que precede e prossegue antes, durante e depois do processo ensinoaprendizagem.

A questão do fracasso escolar pode ser pensada sob o universo do aluno, seja em função da realidade socioeconômica e cultural em que está inserido, ou então, nas relações e nas condições que a escola oferece às crianças em seu processo de construção e apropriação do conhecimento.

Abdicar do gozo exige também uma interpretação radical. Gozo, num sentido metafreudiano, significará para Lacan algo além do princípio do prazer: "O gozo é o que o sujeito procura além dos objetos de sua cobiça na suas condutas repetitivas, e que podem muito bem ser o sofrimento ou a morte", (Cordié, 1996,21) 
Para analisar o fracasso (e mesmo o êxito) escolar é preciso entender que além dos desejos inconscientes que trafegam em mãos duplas na relação ensinante-aprendente, existe o fenômeno da "transferência" nesta díade.

\subsection{O fracasso escolar e o trabalho psicopedagógico}

Intervir (vir entre): A problemática da aprendizagem é uma realidade alienante e imobilizadora que pode apresentar-se tanto individual quanto coletivamente. Em sua produção, intervêm fatores que dizem respeito ao socioeconômico, ao educacional, ao emocional, ao intelectual, ao orgânico e ao corporal.

A psicopedagogia clínica comprova que embora seja necessário trabalhar e estudar os determinantes enunciados (orgânicos, sociais, políticos, etc) a capacidade de pensar e aprender ainda podem subsistir nas situações educativas, sociais, econômicas e orgânicas mais desfavoráveis.

Inscreve-se como tarefa, a busca de mudança para os serviços de saúde mental em geral, em busca de articular os diferentes enfoques profissionais e os importantes recursos humanos com os escassos recursos econômicos e institucionais, para satisfazer a ampla demanda de assistência e a urgente necessidade de promoção de saúde na aprendizagem.

A psicopedagogia vem para explicar também que na fabricação do problema de aprendizagem como sintoma intervém questões que dizem respeito à significação inconsciente do conhecer e do aprender e ao posicionamento diante do escondido.

Portanto, a psicopedagogia ou o psicopedagogo que atua em um ambiente de educação, deverá possuir uma grande variedade de conhecimentos, pois terá que dar conta dos fenômenos transferenciais em suas diversas manifestações. Deverá conhecer questões que dizem respeito ao grupal e ao institucional.

Um dos propósitos do trabalho psicopedagógico na escola consiste em conseguir que o fracasso escolar não seja a denúncia que renuncia a denunciar. Ante uma intervenção deverá ocorrer uma mudança de posição, o reconhecer-se pensante.

O fracasso escolar ou o problema de aprendizagem deve ser sempre um enigma a ser decifrado que não deve ser calado, mas escutado. Quando o "não sei" aparece como principal resposta pode-se perguntar o que é que não está permitido saber.

A escuta não se dirige aos conteúdos não-aprendidos, nem aos aprendidos, nem às operações cognitivas não-logradas ou logradas, nem aos condicionantes orgânicos, nem aos inconscientes, mas às articulações entre essas diferentes instâncias. Não se situa no aluno, nem no professor, nem na sociedade, nem nos meios de comunicação como ensinantes, mas nas múltiplas relações entre eles. 
Para poder se ter uma percepção acerca da existência ou não de patologias estruturadas no aprender (sintoma-inibiçãotranstornos de aprendizagem reativo), a visão orientar-se-á por meio da relação do sujeito com o conhecimento. Não existe nem uma única causa, nem situações determinantes do problema de aprendizagem.

$\mathrm{O}$ aprender transcorre no seio de um vínculo humano cuja matriz toma forma nos primeiros vínculos mãe-pai-filho-irmão, pois a prematuridade humana impõe a outro semelhante adulto para que a criança, aprendendo e crescendo, possa viver.

Para dar conta das fraturas no aprender, necessita-se atender aos processos, à dinâmica ao movimento, às tendências e não aos resultados ou rendimentos (sejam escolares ou psicométricos).

Sinteticamente, segundo Fernández (1991) a resposta ao interrogador sobre como ler psicopedagogicamente a produção de um paciente, de uma família, ou de um grupo, pode resumir-se assim: posicionando-se em um lugar analítico e assumindo uma atitude clínica, à qual será necessário incorporar conhecimentos, teoria e saber, acerca do aprender.

O saber psicopedagógico pode ser obtido a partir de um trabalho de auto-análise das próprias dificuldades no aprender, pois a formação do psicopedagogo, assim como requer a transmissão de conhecimentos e teorias, também requer um espaço para a construção de um olhar e uma escuta psicopedagógicos.

Como psicopedagogo, se está inserido em diversos sistemas e realizam-se atividades em diferentes níveis, portanto esse trabalho consiste em ajudar a promover mudanças, contribuir com uma visão diferente.

A prática psicopedagógica ampla, atuando com a escola, a família e a sociedade em sua totalidade, poderá apontar perspectivas de mudanças. A partir da consciência da função mediadora nos processos de aprendizagem, seja no pedagógico ou no social, serão delineados os paradigmas já ultrapassados.

\subsection{Os responsáveis pelo fracasso escolar}

Quando se fala em fracasso, supõe-se algo que deveria ser atingido. Ele é definido por um mau êxito em quê? De acordo com que parâmetro? Como a sociedade atual define o que é sucesso? Deve-se analisar o fracasso escolar de forma ampla, considerando-o como peça resultante de muitas variáveis.

A busca pelos culpados de tal fracasso acaba sendo um jogo onde ora se culpa a criança, ora a família, ora uma determinada classe social, ora todo um sistema econômico, político e social. Fernández (1994) lembra que a culpa, o considera-se culpado, em geral, está no nível imaginário e coloca que o contrário da culpa é a responsabilidade. Para 
ser responsável por seus atos, é necessário poder sair do lugar de culpa.

Em que medida existe resposta à pergunta sobre por que o aluno não aprende. A construção do conhecimento, sabe-se que é permanente e sucessiva, a negativa (não aprende) torna-se incoerente. Segundo Freire (1979) a educação crítica considera os homens como seres inacabados, incompletos em uma realidade igualmente inacabada e juntamente com ela. Portanto, em permanente processo de aprendizagem (ainda não aprendeu).

Geralmente, aqueles que vivem o fracasso escolar vêm marcados por múltiplos insucessos nos vários lugares que ocupam: na família, na escola, no grupo social, onde percebem que não dão conta de responder às expectativas dos outros, estando sempre aquém. Ou são constantemente criticadas, ou se criticam.

O sintoma problema de aprendizagem implica o fracasso da simbolização ante a anulação do desconhecimento. É preciso continuar a acreditar que os possíveis sintomas que geram o insucesso escolar sejam vistos num prisma amplo, considerados de modo diverso, em consonância com o todo de cada aprendente, em contextos mais gerais e com sentidos e significados maiores. Assim, o sucesso na aprendizagem pode ser vivenciado em muitas parcerias, na busca dos motivos que se apresentam no não-aprender, será a história de cada um, o ponto de partida, pois o essencial é considerar o mundo de cada aprendente, com suas singularidades. Então, deve-se refletir sobre o que se deve valorizar, um resultado de teste ou a realidade, a vida de uma criança. São crianças que passam numa prova de ritmo e sabem fazer uma batucada. Que não têm equipamentos e coordenação motora e andam em muros e árvores. Que não têm discriminação auditiva e reconhecem o canto dos pássaros. Crianças que não sabem dizer os meses do ano, sabem a época de plantar e colher. Não conseguem aprender os rendimentos da aritmética e, na vida, fazem compras, sabem lidar com o dinheiro, são vendedoras de feira. Não têm memória e discriminação visual, mas reconhecem uma árvore pelas folhas. Não têm coordenação motora com o lápis, mas constroem pipas. Não têm criatividade e fazem seus brinquedos do nada. Crianças que não aprendem nada, mas aprendem e assimilam o conceito básico que a escola lhes transmite, qual seja, o mito da ascensão social, da igualdade de oportunidade e depois assumem toda a responsabilidade pelo seu fracasso escolar.

Como nos diz Lima e Moysés (1982), o aprendente pode estar em dificuldades no seu aprender, mas todas as situações são passíveis de mudança. Se a aprendizagem é resultante, de um conjunto processual de vínculos entre ensinantes e aprendentes, cabe cuidarmos de nossas subjetividades, aprendendo que colocamos em jogo nossos herdados organismos, nossos corpos e nossas inteligências, constituídos em nossas 
interações uns com os outros e, com as múltiplas dimensões da vida humana.

Portanto, fracassamos todos nós, os que ensinam, os que são ensinados e todos os demais integrantes desta sociedade. E fracassamos não simplesmente nas tarefas de propiciar ao indivíduo que estuda uma oportunidade de seguir seus estudos, de obter um diploma ou de se inserir no mercado de trabalho, posto que essas são apenas algumas das faces da ação educativa.

\subsection{O Fracasso Escolar e a Avaliação}

Segundo Dantas (2001), o Fracasso Escolar é um sintoma que causa um mal-estar que atinge todo o universo do aprendente, na sala de aula, mal-estar na sua família, malestar na cultura. É cobrado de uma criança que responda ao que o meio, ao que a educação lhe impõe, tendo que se ajustar às normas, e quando algo interrompe isto, são rotuladas de não inteligentes ou débeis mentais. Todo sintoma é um ato, o sujeito em lugar de dizer, faz.

Não tendo como abster de se falar de processo de aprendizagem sem mencionar avaliação, destaca-se um fragmento do trabalho dos autores Melo e Cols (2007), apresentado no VIII Congresso de Psicologia Escolar e Educacional, onde eles nos dizem que diante do fracasso na aprendizagem da língua escrita nas escolas brasileiras, os estudos que conduzem ao desenvolvimento de instrumentos de avaliação que possam contribuir para a compreensão dos obstáculos que os aprendizes apresentam nesse processo, são considerados de grande relevância. Os sistemas tradicionais de avaliação das dificuldades de aprendizagem escolar adotadas pela Psicologia tendem a ignorar a natureza interativa do ensino e da aprendizagem, atribuindo, em geral, a responsabilidade do fracasso escolar à criança ou ao seu meio social (Dockrell \& McShane, 2000; Mota, 2005; Proença, 1997). Historicamente, ainda tem prevalecido tanto o modelo médico e patologizante quanto o padrão psicométrico de avaliação. Alguns problemas nas aprendizagens escolares fundamentais podem ser transitórios, no entanto, alguns aprendentes apresentam dificuldades mais persistentes. Mais recentemente, o enfoque cognitivo de referência vem afirmando a importância de uma avaliação que leve em conta a tarefa, além da criança e do contexto.

Com o objetivo de proporcionar novo campo explicativo para a questão do êxito escolar e do fracasso escolar, faz-se necessário estabelecer que na prática psicopedagógica, valorizar o sujeito e sua forma de aprender, levando em conta a relação que o mesmo estabelece com o aprendizado, cuidando para que aquilo que é sintomático não se transforme em estrutural.

O fracasso escolar representa um sintoma e não uma debilidade cognitiva ou intelectual. Deve-se levar em conta, nos alerta 
Cordié(1996) a existência daqueles cujo fracasso escolar não impediu que fossem bem sucedidos na vida e que vangloriam isso; e há também os que jamais se refizeram dele; e os que, felizmente em maior número, nunca o conheceram.

Atualmente, temos visto reacendidas as discussões a respeito da determinação da inteligência e de como avaliá-la. Por um lado, a crença em uma inteligência que depende exclusivamente da herança genética, e, por outro, a ênfase em aspectos emocionais, como a capacidade para lidar com as próprias emoções, nas conquistas do indivíduo. Mas ambas nos convidam a enfatizar as "habilidades individuais" como sendo fator pelo sucesso ou fracasso do sujeito.

O que buscamos hoje é a evolução, a qualidade e a produtividade nos processos de ensino-aprendizagem, a fim de formar uma nova geração de pessos comprometidas com a ética, com valores coletivos, com o mundo e a informação democratizados. Em síntese, buscamos mais humanidade e justiça nesses tempos de grandes avanços tecnológicos.

Ao falarmos em justiça na educação, pensamos também em avaliação, pois ela é uma forma representativa das relações entre aluno, aprendizagem, professor, escola e vida.

Essa complexidade que cerca o ser humano e o seu acesso ao conhecimento deve ser considerada em qualquer avaliação. Por isso, é preciso buscar métodos formativos e contínuos de avaliação, que contemplem a realidade e estejam fundamentados na observação dos aprendentes.

Evoluir em avaliação é acompanhar o ser humano integralmente. É ouvir, ver, sentir, tocar, relacionar...integrar.

\section{CONSIDERAÇÕES FINAIS}

A sociedade busca cada vez mais o êxito profissional, a competência a qualquer custo e a escola também segue esta concepção. Aqueles que não conseguem responder às exigências da instituição podem sofrer com problemas de aprendizagem. O fracasso é o oposto ao êxito. Faz-se necessário reverter esta ética do êxito.

Buscar soluções para o fracasso escolar não consiste em patologizar o aprendente, mas em ampliar este foco, abrindo espaço para outras variáveis que também influenciam no processo da aprendizagem como a instituição, o método de ensino, as relações ensinante aprendente, os aspectos sócios-culturais, a história de vida do sujeito.

Portanto, é necessário que a psicopedagogia e, ou, que o objeto de qualquer intervenção psicopedagógica abra espaços objetivos e subjetivos de autoria do pensamento. Ou seja, para resolver o fracasso escolar do aluno deve-se intervir no sistema ensinante, propiciar modalidades de aprendizagem que potencializem as possibilidades singulares de cada indivíduo. 
A oficina psicopedagógica tem $\mathrm{o}$ intuito de desejar construir uma práxis participativa e dialógica que respeite a trajetória de cada aprendente ensinante, de cada ensinante aprendente.

\section{REFERÊNCIAS}

AQUINO, Julio Groppa (org.) Erro e fracasso na escola: alternativas teóricas e práticas -. São Paulo: Summus, 1997.

AURÉLIO, Online. Disponível em $<$ http://200.225.157.123/dicaureliopos/login.a sp>. Acesso em: 14 set. 2013.19:30.

BEAUCLAIR, João. Do fracasso escolar ao sucesso na aprendizagem: proposições psicopedagógicas. Rio de Janeiro; WaK , 2008

BECKER, Fernando. Da ação à operação: o caminho da aprendizagem: $J$. Piaget e P. Freire. Porto Alegre; EST: Palmarinca: Educação e Realidade. 1993.

BOSSA Nádia Aparecida. Fracasso Escolar, um olhar psicopedagógico. Porto Alegre: ARTMED, 2002.

BOSSA, Nadia Aparecida. Sintoma escolar: uma questão de sentido e direção. Psicologia em Estudo, São Paulo, v. 2, p. 20-57, 2002.

CORDIÉ Anny. Os atrasados não existem: Psicanálise de crianças com fracasso escolar. Porto Alegre: Artes Médicas Editora, 1996.

DANTAS, Andreneide. Sobre a problemática da Educação Infantil.

Disponivel em:

<www.escutaanalitica.com.br/problematicas. htm>., Acesso em: 08/02/2013.16:30.

FERNÁNDEZ, Alicia. A Inteligência Aprisionada. Porto Alegre: Artemed, 1991
Os Idiomas do Aprendente. Porto

Alegre: Artemd, 2001. Apud. P. 29, 30

Soledad Lugones(1999)

A Inteligência aprisionada:

abordagem psicopedagógica clínica da criança e sua família. Porto Alegre: Artes Médicas, 1995.

FREIRE, Paulo. Conscientização: teoria e prática da libertação: uma introdução ao pensamento de Paulo Freire. São Paulo; Cortês e Moraes, 1979.

FREUD, Sigmund. (1926-1925). Inibições, sintoma e angústia. In: Obras completas. Vol. XX. Rio de Janeiro: Imago, 1976.

HOFFMANN, Juçara. Avaliação mediadora Uma prática em construção da pré-escola à universidade. Porto Alegre: Mediação, 2006

LACAN, Jacques. O seminário, livro 1: os escritos técnicos de Freud. Rio de Janeiro: Jorge Zahar, 1979.

LIMA, Gerson Zanetta de, e MOYSÉS, Maria Aparecida A. desnutrição e fracasso escolar: Uma relação tão simples? Revista da Ande, v. 1, n. 5, p. 57-61, 1982.

MELO, Rosane B., et al. Avaliação das dificuldades de aprendizagem na leitura $e$ na escrita. VIII CONPE, 2007. Disponível em < http://www.viiiconpe.psc.br/.> Acesso em 18 de ago. 2013. 20:22.

RUBISINSTEIN, Edith. Psicopedagogia uma prática, diferentes estilos. São Paulo: Casa do Psicólogo, 1999.

SISTO, Francisco Firmino. (2001).

Dificuldades de aprendizagem no contexto psicopedagógico (pp. 190-213). Petrópolis: Vozes.

WEISS, Maria Lúcia Lemme. Psicopedagogia Clínica uma visão diagnóstica dos problemas de aprendizagem escolar.4. ed. Rio de Janeiro: DP \&A, 1997. 